\title{
Estilos de Aprendizagem e Condições de Estudo de Alunos de Psicologia*
}

\section{Learning Styles and Study Conditions of Psychology Students Estilos de Aprendizaje y Condiciones de Estudio de los Estudiantes de Psicología}

\section{Katya Luciane de Oliveira}

Psicóloga. Doutora em Psicologia, Desenvolvimento Humano e Educação pela Faculdade de Educação da Unicamp. Mestre em Psicologia pelo Programa de Estudos de Pós-graduação Stricto-Sensu em Psicologia da Universidade São Francisco. Professora adjunta do curso de Psicologia e do Programa de Mestrado e Doutorado em Educação da Universidade Estadual de Londrina.

\section{Angélica Polvani Trassi}

Psicóloga. Especialista em Avaliação Psicológica pela Universidade Filadélfia. Mestranda em Educação pelo Programa de Mestrado em Educação da Universidade Estadual de Londrina.

\section{Amanda Lays Monteiro Inácio}

Psicóloga. Mestranda em Educação pelo Programa de Mestrado em Educação da Universidade Estadual de Londrina.

\section{Acácia Aparecida Angeli dos Santos}

Psicóloga. Doutora em Psicologia Escolar e do Desenvolvimento Humano pela USP, Docente da graduação no curso de Psicologia e no Programa de Pós-graduação Stricto-Sensu em Psicologia, da Universidade São Francisco-SP.

*Agência de fomento: CNPq

\section{Resumo}

Este estudo objetivou analisar os estilos de aprendizagem e as condições de estudo de estudantes de Psicologia. Participaram 192 estudantes de duas universidades (pública e privada) do estado do Paraná. Foi aplicado, coletivamente, um questionário visando identificar os estilos de aprendizagem e as condições de estudo. Os resultados evidenciaram que os estudantes dormem tarde e na sala de aula sentem-se cansados e sonolentos. Também foi observado que a atividade em grupo é a mais escolhida entre os estudantes, especialmente em situações de avaliação da aprendizagem. Fora do ambiente universitário, o estudo ocorre simultaneamente com outras atividades como assistir à televisão, acessar às redes sociais etc. Dessa forma, identificou-se que o ambiente de estudo não está estruturado de forma que favoreça a atividade de leitura e estudo. Assim, este estudo discorre sobre as implicações pedagógicas e psicoeducacionais.

Palavras-chave: aprendizagem; estudo; universidade.

\section{Abstract}

This research investigates the learning styles and study condition of Psychology students. The sample is composed by 192 students from two universities (public and private) from Parana state. It was applied a questionnaire focusing the student's learning style and the study conditions. The results have showed that students sleep late and in the classroom feel tired and sleepy. It also became evident that the group activity is the choice among students, especially when it is configured as assessing learning. Outside the university environment the study is simultaneously with other activities such as watching television, get on social networks, among others. Another fact is that the learning environment is not quiet, because it seems they do not have a place/space dedicated to the study. Pedagogical and psycho-educational implications are discussed.

Keywords: learning; study; university

Resumen

Este estudio tuvo como objetivo analizar los estilos de aprendizaje y las condiciones de estudio de estudiantes de Psicología. Participaron 192 estudiantes de dos universidades (pública y privada) de la província de Paraná. Fue aplicado, colectivamente, un cuestionario buscando identificar los estilos de aprendizaje y las condiciones de estudio. Los resultados mostraron que los estudiantes duermen tarde y en la clase se sienten cansados y con sueño. También fue observado que la actividad en grupo es la más elegida entre los estudiantes, sobre todo en situaciones de evaluación del aprendizaje. Fuera del entorno universitário, el estudio ocurre simultáneamente con otras actividades como ver la televisión, accesar las redes sociales, etc. De esta maneira, se identificó que el entorno de estudio no está estructurado de forma que favorezca la actividad de lectura y estudio. Así, este estudio discute sobre las implicaciones pedagógicas y psicoeducacionales.

Palabras-clave: aprendizaje; estudio; universidad. 
A sociedade se encontra em constante desenvolvimento e cada vez mais preza pelo conhecimento, informação e aquisição de novas habilidades. Na literatura científica, há uma busca para se compreender como ocorre o processo de aquisição do conhecimento, apontando para a relevância das diferenças individuais em situações de aprendizagem e para a necessidade de ampliar as considerações sobre como se aprende (Santos, Amadi, \& Oliveira, 2005).

Desse modo, para Sternberg $(1987,2000)$, o campo de estudo que visa a entender de que forma o indivíduo aprende, armazena e recorda seus pensamentos e emoções refere-se à Psicologia Cognitiva, sendo a teoria do processamento da informação a área responsável por estudar a maneira como os novos conhecimentos são processados. Baseada no Cognitivismo, para essa teoria a mente humana funcionaria como uma estrutura básica com movimento semelhante a um sistema de processamento de um computador, que processa e armazena as informações e as impressões recebidas do meio (Díaz, 2011; Oliveira, Boruchovitch, \& Santos, 2009).

A teoria do processamento da informação compreende que os novos conteúdos serão captados pelos órgãos do sentido (visão e audição), em um processo denominado de memória sensorial. Esse momento necessita de atenção para direcionar o foco das informações por certo período de tempo. Posteriormente, os conhecimentos serão armazenados na memória de curto prazo, por período limitado de tempo, na sequência, a nova informação será armazenada na memória de longo prazo, de forma duradoura. Contudo, o aprendizado só ocorrerá quando o indivíduo criar conexões entre o novo conteúdo e o conhecimento já adquirido previamente (Bzuneck, 2004; Schunk \& Zimmerman, 2003).

Embora aprender seja uma característica própria da espécie humana, comum a todas as pessoas, a forma como o processo de aprendizagem ocorre é particular a cada indivíduo, ou seja, em função de suas especificidades e diferenças. Assim, o indivíduo constrói seu conhecimento por meio da interação entre as informações captadas e a interpretação que faz delas com base em suas próprias experiências (Santos \& Mognon, 2010). Para Almeida (1992), a preocupação dos pesquisadores diz respeito à forma como as pessoas processam a informação, compreendem e resolvem as situações-problema. De acordo com Oliveira, Santos, e Scacchetti (2016), são observados diversos padrões de aprendizagem em diferentes tarefas escolares. Nessa direção, algumas variáveis podem contribuir para o desempenho escolar dos alunos, tais como os estilos de aprendizagem e as condições de estudo envolvidas no processo de aprender, construtos abordados no presente trabalho.

Thompson e Crutchlow (1993) definiram os estilos de aprendizagem como a forma preferida de alguém interagir com as situações de aprendizagem. A partir de então, alguns autores (Oliveira et al., 2016; Santos et al., 2005; Santos \& Wechsler, 2008) buscaram estudar tal construto em universitários brasileiros. Para Oliveira et al. (2016) e Santos et al. (2005), os estilos de aprendizagem podem ser considerados como o modo dos indivíduos se relacionarem com as condições de aprendizagem e favorecerem o processamento da informação. Nessa concepção, os estilos de aprendizagem abrangem habilidades como atenção, motricidade, percepção, pensamento, memória, aprendizagem e resolução de problemas.

Autores como Santos e Wechsler (2008) indicam que os estilos de aprendizagem são nomeados como as diferenças existentes na maneira como cada ser humano irá aprender, pois cada indivíduo participa ativamente na construção de seus conhecimentos, sendo assim, suas características pessoais e preferências influenciam diretamente sobre a forma como irá construir novos saberes. Nesse contexto, o estilo pode ser compreendido como sendo a maneira peculiar que cada indivíduo emprega para obter conhecimentos. Kuri (2004) e Uhrig (2015) ressaltam ainda que os estilos descrevem a maneira característica de cada pessoa para aprender, referindo-se à forma empregada por um indivíduo na absorção, processamento e produção de novos conhecimentos.

No que concerne às diferenças de nomenclatura no campo dos estilos, Oliveira et al. (2016) e Zhang e Sternberg (2005), evidenciam as incoerências existentes, ressaltando que ao longo de décadas de estudo, várias terminologias surgiram com a finalidade de buscar entender a maneira particular de cada indivíduo processar as informações, pensar e aprender. Na literatura podem ser encontrados conceitos como: estilos cognitivos, de pensamento, de tomada de decisão, de resolução de problema, de aprendizagem, estilos intelectuais, dentre outros.

Nesse sentido, Santos e Mognon (2010) afirmam que os estilos de aprendizagem diferem dos estilos cognitivos, pois são ações de menor exigência no processamento cognitivo e mais especificamente relacionadas à preferência do sujeito no momento do estudo. Tratando-se de uma preferência definida, não pelo perfil de processamento (foco dos estilos cognitivos/intelectuais), mas por fatores de menor complexidade como os recursos utilizados no momento da aprendizagem, aspectos pessoais próprios do aluno, condições da socialização do aluno, dentre outros.

No que se refere aos estilos de aprendizagem não se pode afirmar a existência de um quantum negativo ou positivo em relação às preferências (Santos \& Mognon, 2010). Constata-se, contudo, a prevalência de estilos distintos entre os alunos, sem que haja um determinado perfil ou estilo para aprender com maior ou menor valor em relação ao outro (Muhlbeier \& Mozzaquatro, 2011). Para CanoGarcia, e Hughes (2000), os estilos dos estudantes podem ser determinados de acordo com um conjunto de fatores, tais como: contexto escolar, métodos de avaliação e de ensino.

Estudar e compreender os estilos de aprendizagem dos alunos é importante, uma vez que eles podem explicar o motivo pelo qual algumas estratégias de aprendizagem 
funcionam melhor do que outras. Quando o docente tem conhecimento sobre o estilo de aprendizagem do aluno, facilita o desenvolvimento e a utilização de metodologias e técnicas de ensino, motivando assim a geração de melhores resultados na aprendizagem (Muhlbeier \& Mozzaquatro, 2011). Entretanto, Santos e Mognon (2010) ressaltam que a escola ainda segue o modelo educacional homogêneo, ou seja, desconsidera as diferenças na forma de aprender dos alunos, e como consequência, o conhecimento não se torna igualmente acessível a todos.

Desse modo, a compreensão dos estilos de aprendizagem se faz de grande relevância para a consolidação do conhecimento. Kuri, Silva, e Pereira (2006) e Maric, Azizifar, e Gowhary (2015) ressaltam que o autoconhecimento permite que o estudante aprenda mais sobre seus pontos fortes e fracos em relação à forma de aprender, fazendo também com que o próprio professor se beneficie em virtude de poder planejar as experiências de aprendizagem e consequentemente favorecer todos os diferentes estilos de aprendizagem utilizados por seus alunos. À medida que o professor toma consciência de que cada estudante tem sua própria maneira de aprender e de se relacionar, passa a promover um ensino orientado por esses parâmetros, utilizando estratégias que promovam um aprendizado mais eficaz e duradouro.

Diversas pesquisas, em âmbito nacional, têm se destinado a investigar os estilos de aprendizagem em estudantes universitários, tais como Oliveira (2012), Santos, Moraes, Rodrigues, e Evangelista (2013), Santos e Mognon (2010). No entanto, evidenciou-se a falta de homogeneidade nos modelos teóricos utilizados. Assim, alguns trabalhos fizeram uso da teoria de Felder e Silverman (1998), outros utilizaram o modelo de Kolb (1984), dificultando a análise dos estilos de aprendizagem dessa população.

Além dos estilos de aprendizagem, outros aspectos estão envolvidos no contexto do ensino e da aprendizagem, tais como as condições de estudo dos alunos, que podem ser definidas como a investigação do sistema de ensino, dos problemas referentes aos processos de aprendizagem e principalmente da maneira como se constitui o ambiente de estudo no qual o universitário está inserido (Oliveira \& Oliveira, 2007). Nota-se, no entanto, a escassez de produção acerca do referido tema, haja vista que poucos estudos nacionais foram encontrados e estes não são atuais.

Nessa direção, Mercuri (1994) afirma que diversas atividades acadêmicas são realizadas fora da sala de aula, tais como leitura, pesquisa bibliográfica, trabalhos, preparação para provas, dentre outras. Com base nisso, os espaços utilizados pelos alunos para estudar são em sua maioria as bibliotecas centrais e setoriais da universidade e também suas residências. Contudo, nem sempre esses locais fornecem condições apropriadas de estudo, uma vez que estão sujeitos a barulhos, por parte de pessoas, aparelhos de TV bem como interferências que estão fora do controle do acadêmico.
Careli e Santos (1998) identificaram duas condições de estudo relevantes para os universitários: temporais e pessoais. A primeira diz respeito ao tempo que o aluno dedica ao estudo, trabalhos e outras atividades acadêmicas. As condições pessoais se referem às habilidades (e estado) do indivíduo necessárias para o desempenho acadêmico bem como saúde física - importante para a aquisição de conhecimento. Mercuri (1994) considera quatro tipos de condições de estudo: espacial - lugares físicos e sociais onde a atividade de estudo ocorre; material - relacionado a todos os materiais e objetos necessários para a aprendizagem; temporal - referente ao tempo destinado ao estudo e pessoal, ou seja, os comportamentos do estudante e; saúde física, necessária para alcançar um bom desempenho escolar. A partir disso, foram realizados alguns trabalhos destinados a investigar as condições de estudo em âmbito nacional nos estudantes universitários, tal como apresentado a seguir.

Mercuri (1994) investigou as condições de estudo de 467 alunos dos cursos de ciências biológicas e da saúde, humanas, exatas e tecnológicas de uma universidade pública. Seu resultado apontou que a maioria dos alunos não possuía regularidade no tempo de estudo, além de não considerarem que possuem tempo suficiente para realizar as atividades acadêmicas, devido à extensa carga horária das disciplinas cursadas. Da mesma forma, em decorrência no número de horas-aula, o sono e o cansaço surgem como condições inadequadas de estudo.

Com propósito similar, a pesquisa de Carelli e Santos (1998) mostrou que a maioria dos estudantes de graduação (Psicologia, Farmácia e Engenharia Civil) que participaram da sua pesquisa $(n=181)$, relatava não ter tempo suficiente para desenvolver suas tarefas, o que ocorria predominantemente nos finais de semana e com alunos de cursos noturnos. Além disso, o sono e o cansaço apareceram como condições pessoais interferentes no rendimento acadêmico.

Anos depois, Oliveira e Oliveira (2007) também observaram que estudantes $(n=138)$ dos cursos de Radiologia, Psicologia e Ciências Contábeis, do período noturno, trabalhavam e dormiam, em média, de 6 a 8 horas por dia. Além disso, a maioria afirmou adequar a rotina de leitura entre os horários de almoço e lanche.

Basso, Graf, Lima, Schmidt, e Bardagi (2013) realizaram uma oficina de organização e métodos de estudo em estudantes da Universidade Federal de Santa Catarina (UFSC), sendo que, previamente foi realizada uma triagem com os alunos interessados em participar. Nesse sentido, foi identificado que a maior parte dos alunos possuía dificuldades para organizar seu tempo e seus estudos, bem como possuíam problemas para se concentrar na aula. Contudo, o trabalho não trouxe detalhes sobre como ocorria o gerenciamento do tempo por parte dos alunos, uma vez que seu foco era a intervenção.

Verifica-se, portanto, que as maiores dificuldades dos estudantes universitários, no que diz respeito às condições de estudo, são o cansaço e a sonolência nas aulas e atividades 
acadêmicas, assim como falta de tempo para realizar as tarefas, devido à carga horária extensa das aulas e ao período de trabalho. Esses resultados corroboram os achados de Watanabe, Cassetari, Santos, Lombard-Platet, e Di Domenico (2001) que afirmam que as principais dificuldades encontradas pelos estudantes universitários se devem a hábitos inadequados de estudo.

Cabe ressaltar a importância da autorregulação do aluno para que ele saiba utilizar as estratégias de aprendizagem e possa acessar seus conhecimentos internos e externos a fim de concretizar o aprendizado, gerenciando seu tempo e modificando a estrutura do seu ambiente físico (por exemplo, local de estudo, deixando-o livre de estímulos que o distraiam) e social (sendo capaz de saber quando necessita fazer uma tarefa sozinho ou com auxílio de outras pessoas), a fim de que consiga administrar e melhorar seu desempenho escolar a partir do estabelecimento de objetivos e metas (Dembo, 2000; Marini \& Boruchovitch, 2014).

Tendo em vista que os estilos de aprendizagem e as condições de estudo promovem a interação do aluno com o processo de aprendizagem, eles podem contribuir para um melhor autoconhecimento e rendimento acadêmico. Face ao apresentado, o presente estudo teve como objetivo identificar de forma exploratória os estilos de aprendizagem e as condições de estudo de estudantes do curso de Psicologia.

\section{Método}

\section{Participantes}

Participaram 192 universitários do curso de Psicologia de três universidades de grande porte (uma pública, 59,38\%, $\mathrm{n}=114$ e duas privadas, $40,62 \%, \mathrm{n}=78$ ) do estado do Paraná. A média de idade foi de 21 anos $(D P=4,1)$, sendo a idade mínima 17 e a máxima 49 anos. O sexo feminino foi predominante na amostra $58,85 \%(n=113)$.

\section{Instrumento}

Foi aplicado um questionário descritivo de cunho qualitativo baseado no instrumento desenvolvido por Oliveira e Oliveira (2007). O instrumento levanta os estilos de aprendizagem e as condições de estudo de universitários. O instrumento na versão de 2007 apresentava 34 questões e na versão utilizada neste estudo apresentava 40 . As alternativas de respostas estavam dispostas em escala likert de 3 pontos (sempre, às vezes e nunca), sempre apresentando uma categoria aberta de resposta. Também é importante informar que 13 questões apresentavam categorias de respostas para que o estudante escolhesse a que mais lhe representava. Um exemplo de questão seria: Quais os locais de estudo em casa você usa para estudar?
Escrivaninha ( ), Não tem lugar fixo ( ), Sentados no sofá ( ), Deitados na cama ( ), Em outro lugar da casa. Qual?

\section{Procedimento}

A pesquisa foi submetida e aprovada pelo Comitê de Ética em Pesquisa (CEP) da Universidade à qual está vinculada. Todos os procedimentos éticos para a realização deste estudo estão fundamentados nos dispositivos da Resolução 466/2012 e complementares do Conselho Nacional de Saúde.

Por ocasião da coleta de dados, foi realizado um rapport entre as pesquisadoras e os estudantes para que a aplicação iniciasse. As aplicações ocorreram de forma coletiva em sala de aula, com duração aproximada de 30 minutos nos estudantes que concordaram com a participação, assinando o termo de consentimento livre e esclarecido.

\section{Análise de dados}

Os dados foram organizados em planilha e submetidos à estatística descritiva. As respostas às questões abertas passaram por análise de conteúdo, o que permitiu a categorização das informações dadas pelos estudantes.

\section{Resultados}

No que tange a primeira questão, acerca das condições de estudo, foi questionado sobre a jornada de trabalho dos estudantes. Assim, a carga horária diária de trabalho de $12,50 \%(n=24)$ era de 4 horas por dia, 6,77\% $(n=13)$ de 6 horas, $27,08 \%(n=52)$ de 8 horas e a maior parte $(53,65 \%$; $\mathrm{n}=103$ ) respondeu que não trabalhava ou possuía cargas horárias diferenciadas que permitia total flexibilidade para estudar. Desse percentual que não trabalhava 50,52\% ( $\mathrm{n}=$ 97) eram alunos de universidade pública.
O horário que os estudantes costumavam dormir e o número de horas dormidas foram questionados. Houve aqueles que costumavam ir dormir entre 22 e 23:00 horas $(10,94 \%, \mathrm{n}=21)$. Uma parte $(21,87 \% ; \mathrm{n}=42)$ respondeu que costumava dormir entre 23 e 24:00 horas e a maioria, $67,19 \%(\mathrm{n}=129)$ dormia depois das $24: 00$ horas. As respostas indicaram que no geral os estudantes não possuem muitas horas de sono, conforme consta na Tabela 1.

Dos que dormiam menos de 6 horas não houve muita 
Tabela 1

Distribuição das frequências e porcentagens de horas de sono dos estudantes

\begin{tabular}{lcc}
\hline Categorias de respostas & $N$ & $\%$ \\
\hline Dormem 8 horas por noite & 27 & 14,06 \\
Dormem pelo menos 6 horas por noite & 62 & 32,29 \\
Dormem entre 6 e 7 horas por noite & 46 & 23,96 \\
Dormem mais que 8 horas por noite & 19 & 9,90 \\
Dormem menos que 6 horas por noite & 38 & 19,79 \\
\hline Total & 192 & 100 \\
\hline
\end{tabular}

diferença entre as instituições pública $(8,85 \%, \mathrm{n}=17)$ e a privada $(10,94 \%, n=21)$. Para complementar a informação foi questionado o motivo de dormirem menos que 6 horas por noite e a categoria 'Costumo ficar até tarde da noite/ madrugada nas redes sociais' foi a resposta mais frequente $(8,33 \%, \mathrm{n}=16)$.

Os horários que os estudantes costumavam acordar pela manhã também foi questionado. Dessa forma, 45,31\% (n = 87) responderam que acordavam diariamente entre $6 \mathrm{e}$ 8 horas da manhã, 31,77\% ( $=61)$ acordavam entre 8 e 10 horas e $19,79 \%(n=38)$ responderam que acordavam depois das 10 horas, sendo que alguns não responderam $(3,12 \%, \mathrm{n}=6)$.

Questionou-se sobre a importância de dedicar tempo de estudo fora do contexto acadêmico/universidade, sendo que a maioria $(92,71 \%, \mathrm{n}=178)$ respondeu que considera importante estudar também fora da universidade. Contudo, uma parte considerável dos estudantes $(53,65 \%$; $\mathrm{n}=103)$ respondeu que estudava 1 hora por dia, outros (31,77\%; $\mathrm{n}=61)$ estudavam de 1 a 2 horas por dia, 3,65\% ( $\mathrm{n}=7$ ) estudavam de 2 a 3 horas, 6,25\% ( $n=12)$ estudavam mais de 3 horas diárias e os demais $(4,69 \%, n=9)$ responderam que estudavam uma quantidade de horas diferente das mencionadas.

Quando questionados sobre em que local da casa estudam, a maioria ( $50 \%, \mathrm{n}=96$ ) não possui lugar fixo; $(27,08 \%, \mathrm{n}=52)$ relata estudar deitado na cama; $(15,62 \%$, $\mathrm{n}=30)$ estudam sentados no sofá e $(7,29 \%, \mathrm{n}=14)$ responderam que estudam em outros lugares da casa (por exemplo, sentados na mesa da cozinha, no quintal etc.).

No que se refere ao ambiente de estudo, perguntou-se a importância que os estudantes davam ao silêncio. A maior parte $(56,25 \% ; n=108)$ respondeu que o silêncio é muito importante em todos os momentos na hora do estudo; $19,27 \%(n=37)$ responderam que frequentemente acham que o silêncio é relevante; $24,48 \%(n=47)$ responderam que raramente priorizam o silêncio. Curiosamente, grande parte disse que prefere estudar em casa escutando música $(59,37 \%, \mathrm{n}=114)$ ou assistindo televisão $(16,15 \%, \mathrm{n}=31)$.

Especificamente sobre as condições de estudo e estilos de aprendizagem em sala de aula foi perguntado quanto à dispersão da atenção durante as aulas. (37,50\%; $\mathrm{n}=72$ ) afirmou que raramente dispersava sua atenção;
$44,27 \%(n=85)$ disseram que a frequência com que se dispersam é muito alta e $18,23 \%(n=35)$ afirmaram que nunca dispersavam sua atenção durante as aulas. No entanto, a maior parte dos alunos admitiu que em algum momento, durante as aulas, costuma entrar em redes sociais $(61,98 \%, \mathrm{n}=119)$.

Aspectos como a assimilação e a organização do conteúdo logo após a explicação do professor também foram levantados. Assim, 41,15\% ( $n=79)$ disseram que frequentemente conseguiam compreender o conteúdo; $50 \%(n=96)$ disseram que sempre conseguiam e $5,73 \%$ ( $n=11$ ) afirmaram que raramente conseguiam entender o conteúdo logo após a explicação. Apenas $(3,12 \%, \mathrm{n}=6)$ deixaram em branco a questão.

Foi questionado se o estudante se sentia cansado ou com sono durante as aulas. $(36,46 \%, \mathrm{n}=70)$ disseram que se sentem cansaço e sono com frequência; $34,90 \%$ ( $n=67$ ) disseram que sempre sentem sono e cansaço, $16,67 \%$ ( $\mathrm{n}=$ 32) raramente; e uma pequena porcentagem (10,94\%; $n$ = 21) respondeu que nunca sente cansaço ou sono; duas pessoas (1,04 \%) não responderam a questão.

No que tange ao tempo de antecipação que o estudante se prepara para uma avaliação, $56,77 \%(\mathrm{n}=109)$ dos estudantes estudam na semana da prova; $30,21 \%$ ( $\mathrm{n}=$ 58) afirmaram estudar às vésperas da prova e somente $13,02 \%(n=25)$ começavam a estudar semanas antes da prova.

Um assunto abordado foi a preferência, ou não, de trabalhos individuais ou em grupo como forma de avaliação. A maior parte se direcionou para atividades que envolvam trabalhos em grupo $(69,27 \%, \mathrm{n}=133)$; $(27,08 \%, \mathrm{n}=52)$ prefere atividade individual e os demais, $(3,65 \%, n=7)$, não se posicionaram. Nesse mesmo contexto, questionou-se a preferência, ou não, por delegar tarefas no grupo. Nessa amostra, a maior parte $(52,60 \%, \mathrm{n}=101)$ disse que prefere delegar.

Também foi perguntado se os estudantes preferiam aulas que envolvessem o uso de tecnologias como datashow, vídeos, dentre outros. A Tabela 2 apresenta as categorias de respostas.

Outro aspecto pesquisado foi que tipo de perfil docente eles preferiam para se interessarem mais pelo estudo. A Tabela 3 apresenta as categorias de respostas. 
Tabela 2

Preferência acerca de recursos multimídia usados em aula

\begin{tabular}{lcc}
\hline Categorias de respostas & $N$ & $\%$ \\
\hline Datashow & 93 & 48,44 \\
Vídeos on-line & 62 & 32,29 \\
TV/vídeos & 20 & 10,42 \\
Músicas & 9 & 4,69 \\
Prefiro aula tradicional sem recursos de apoio & 8 & 4,16 \\
\hline Total & 192 & 100 \\
\hline
\end{tabular}

Tabela 3

Perfil docente preferido para despertar maior interesse do estudo

\begin{tabular}{lcc}
\hline Categorias de respostas & $N$ & $\%$ \\
\hline Humanista & 72 & 37,50 \\
Controlador/dominante & 38 & 19,79 \\
Pouco controlador/dominante & 31 & 16,15 \\
Filosófico & 26 & 13,54 \\
Não tenho opinião sobre isso & 25 & 13,02 \\
\hline Total & 192 & 100 \\
\hline
\end{tabular}

Outro fator questionado foi a preferência por atividades orientadas (pelos professores) que permitissem maior ou menor grau de autonomia. Nessa questão a maior parte $(70,83 \%, \mathrm{n}=136)$ disse que prefere atividades que exijam maior autonomia; e $(22,92 \%, \mathrm{n}=44)$ disse preferir atividades que denotassem menor grau de autonomia; $(6,25 \%, \mathrm{n}=12)$ disseram não ter opinião sobre isso.

\section{Discussão}

Por meio dos resultados expostos até então, verificou-se que a maior parcela dos alunos, não possuía uma jornada de trabalho, ou tinha mais flexibilidade de horários, sendo que desses, 50,52\% eram estudantes de instituições públicas. Em relação às instituições privadas, a maioria exerce uma rotina de trabalho em torno de 8 horas. Niquini et al. (2015) encontraram em seu estudo uma relação positiva entre maior jornada de trabalho e pior desempenho acadêmico, ao passo que alunos com menor carga horária de trabalho apresentam melhores hábitos de estudo. Contudo, ressaltam que as características do trabalho ou atividades desempenhadas pelos alunos podem auxiliar ou prejudicar o rendimento acadêmico.

Entretanto, quando analisadas as condições de estudo, sejam elas temporais ou pessoais dos alunos de Psicologia, verificou-se que esses não apresentam hábitos de estudos adequados. Quanto a isso, no que tange o período de sono e horário de dormir, verificou-se que a maior porcentagem dos alunos dorme pelo menos 6 horas por noite e vai dormir após as $24 \mathrm{~h}$. Um dos principais motivos apontados por eles para dormir pouco tempo foi as redes sociais. Tal hábito contribui para que a maioria dos alunos apresentem sono ou cansaço durante as aulas ou atividades acadêmicas. Da mesma forma, os autores (Carelli \& Santos, 1998; Mercuri, 1994; Oliveira \&
Oliveira, 2007) também identificaram que os universitários apresentavam condições físicas de estudo inadequadas em relação aos hábitos de sono. Ainda sobre isso, Carvalho et al. (2013) afirmam que estudantes universitários têm modificado seu padrão de sono devido às exigências acadêmicas.

Em relação às condições temporais de estudo, constatou-se que a maioria estuda em média uma hora por dia e não tem lugar definido para realizar suas atividades acadêmicas, já que uma parcela da amostra relatou estudar na cama ou sofá. Ainda sobre isso, foi investigado o tempo de preparo dos estudantes de Psicologia para as avaliações, sendo constatado que a maioria estuda na semana ou na véspera da prova. O pouco tempo destinado a desempenhar as atividades universitárias pode ser decorrente do excesso de carga horária das aulas, bem como do cansaço dos alunos para a execução dessas (Carelli \& Santos, 1998; Mercuri, 1994; Oliveira \& Oliveira, 2007). Da mesma forma, Basso et al. (2013) identificaram que muitos estudantes universitários possuíam problemas para organizar o tempo e seus estudos e que, portanto, isso poderia prejudicar seu rendimento escolar.

Por fim, a maioria disse priorizar o silêncio no momento do estudo, podendo se considerar que essa condição facilita a atenção e concentração do aluno para a realização das 
atividades. Contudo, muitos afirmaram que estudam enquanto ouvem música ou assistem TV. Dessa forma, embora um número superior de alunos reconheça a importância do ambiente sem barulho para estudar, eles mantêm hábitos de estudo inadequados. Sobre isso Mercuri (1994) ressalta que nem sempre os alunos estão em contato com ambientes que propiciem tal condição de estudo, uma vez que em suas casas estão submetidas a barulhos por meio de conversa de colegas, barulhos de TV, dentre outros.

Muitos alunos relataram dificuldades para se concentrar durante as aulas, dispersando-se com frequência. Um dos motivos que podem contribuir para isso é o uso recorrente das redes sociais em período de aula. Tal dificuldade de concentração foi relatada por participantes do estudo de Basso et al. (2013). Um aspecto a ser considerado e que tende a contribuir para tal dificuldade, é o número elevado de acadêmicos que dorme tarde e apresenta sonolência e cansaço durante as aulas. A esse respeito, Verri et al. (2008) afirmam que a privação de sono afeta habilidades cognitivas como memória, raciocínio lógico e tomada de decisão, comprometendo a capacidade de trabalho.

Em relação aos estilos de aprendizagem, foi investigado como eles preferem aprender, levando em consideração atividades individuais ou em grupo, recursos didáticos e perfil docente. A grande maioria prefere executar atividades em grupo e aulas que utilizem recursos tecnológicos (datashow e vídeos on-line). Segundo Souza, Murta, e Leite (2016), as metodologias de ensino que se apropriam de tecnologias digitais tendem a favorecer o desempenho escolar dos alunos. Dessa forma, tais recursos tendem a favorecer a compreensão dos alunos sobre a matéria, o que comprova os resultados de que parte significativa da amostra demonstra compreender os conteúdos apresentados em sala de aula.

Em relação ao perfil do professor, 37,5\% dos estudantes investigados preferem docentes que possuem característica humanista. Segundo o humanismo, o docente é um mediador que tem por objetivo facilitar a aprendizagem do aluno e incentivar a autonomia no processo de aprendizagem, bem como relacionar conteúdos da aula com a vida prática do aluno (Souza \& Moura, 2016). Esses dados novamente vão ao encontro com a preferência dos alunos por atividades que exijam mais independência.

Posto ao que foi apresentado, há que se mencionar que o presente estudo teve caráter descritivo exploratório, sendo necessário que em pesquisas futuras sejam usados delineamentos mais sofisticados, além de se recomendar o uso de instrumentos que apresentem evidências de validade para avaliar os fenômenos aqui apresentados. Outro aspecto é a limitação da amostra, que deve ser ampliada e mais diversificada, pensando-se em agregar outros estados. Assim, novos estudos deverão ser realizados.

É voz corrente entre professores universitários que muitos dos estudantes que ingressam no ensino superior trazem consigo lacunas consequentes de uma educação básica falha. E essa percepção dos professores encontra respaldo na literatura científica acerca da formação de estudantes universitários, visto que eles apresentam dificuldades com a aquisição do conteúdo técnico científico com o qual tem contato na formação superior (Mercuri, 1994; Oliveira, \& Oliveira, 2007). Por isso, identificar qual o perfil/estilo do universitário, em razão de seu aprendizado, bem como a condição em que o estudo e a aprendizagem ocorre pode ser um pré-requisito para se traçar médias que possam colaborar para uma formação profissional de qualidade.

No estudo de Oliveira e Oliveira (2007), há quase uma década, já apontava a necessidade de pensar em projetos políticos-pedagógicos mais abrangentes e que pudessem implementar programas interventivos para mapear o perfil do estudante universitário a fim de traçar um plano curricular mais personalizado. Por isso, se há um mapeamento de qual o estilo de aprendizagem desse aluno, bem como em que condições esse aluno estuda, podemos traçar uma forma de melhorar o estudo do aluno em questão.

Também se faz necessária a capacitação dos professores, de modo que estejam aptos a realizar esse mapeamento para assim oferecer um aprendizado mais personalizado. Acredita-se que a formação no ensino superior realmente atingiria seu objetivo: formar um profissional qualificado e crítico, ao executar esse papel. Sob essa perspectiva, esperase que as considerações trazidas pelo presente estudo possam contribuir para ampliar a discussão sobre a formação dos psicólogos no contexto universitário nacional.

\section{Referências}

Almeida, L. S. (1992). Inteligência e aprendizagem: dos seus relacionamentos à sua promoção. Psicologia: Teoria e Pesquisa, 8(3), 277- 292.

Basso, C., Graf, L. P., Lima, F. C., Schmidt, B., \& Bardagi, M. P. (2013). Organização de tempo e métodos de estudo: Oficinas com estudantes universitários. Revista Brasileira de Orientação Profissional, 14(2), 277-288. Recuperado de http://pepsic.bvsalud.org/pdf/rbop/v14n2/12.pdf
Bzuneck, J. A. (2004). Aprendizagem por processamento da informação: uma visão construtivista. Em E. Boruchovitch e J. A. Bzuneck (Orgs.), Aprendizagem: processos psicológicos e contextos social na escola (pp. 1754). Petrópolis: Vozes.

Cano-García, F. \& Hughes, E. H. (2000). Learning and thinking styles. An analysis of their interrelationship and influence on academic achievement. Educational Psychology, 20(4), 413-430. doi: 10.1080/713663755 
Carelli, M. J. G., \& Santos, A.A.A. (1998). Condições temporais e pessoais de estudo em universitários. Psicologia Escolar e Educacional, 2(3), 265-278. Recuperado de http://www. scielo.br/pdf/pee/v2n3/v2n3a06

Carvalho, T. M. C. S., Junior, I. I. S., Siqueira, P. P. S., Almeida, J. O., Soares, A. F., \& Lima, A. M. J. (2013). Qualidade de sono e sonolência diurna entre estudantes de diferentes áreas. Revista Neurociências., 21(3), 383387. doi: 10.4181/RNC.2013.21.854.5p

Dembo, M. H. (2000). Motivation and learning strategies for college success: a self- management approach. Mahwah: Lawrence Erlbaum Associates Publishers.

Díaz, F. (2011). O processo de aprendizagem e seus transtornos. Salvador: EDUFBA.

Felder, R. M., \& Silverman, I. K. (1998). Learning styles and teaching styles in engineering education. Engineering Education, 78(7), 674-681.

Kolb, B. (1984). Functions of the frontal cortex of the rat: a comparative review. Brain Research Reviews, 8(1), 65-98.

Kuri, N. P. (2004). Tipos de personalidade e estilos de aprendizagem: proposição para o ensino de engenharia. (Tese de Doutorado em Engenharia de Produção). Universidade Federal de São Carlos, São Carlos, Brasil.

Kuri, N.P ., Silva, A. N. R., \& Pereira, M. A. (2006). Estilos de aprendizagem e recursos de hipermídia aplicados no ensino de planejamento de transportes. Revista Portuguesa de Educação, Braga,19(2), 111-137. Recuperado de http://www.scielo.mec.pt/pdf/rpe/ v19n2/v19n2a06.pdf

Maric, M., Azizifar, A., \& Gowhary, H. (2015). Differences in learning styles: a comparison of Slovenian Universities. Procedia - Social and Behavioral Sciences, 199, 175-183. doi: 10.1016/j.sbspro.2015.07.079

Marini, J. A., \& Boruchovitch, E. (2014). Estratégias de aprendizagem de alunos brasileiros do ensino superior: Considerações sobre adaptação, sucesso acadêmico e aprendizagem autorregulada. Revista E-Psi, 1, 102126. http://revistaepsi.com/wp-content/uploads/ artigos/2014/Ano4-Volume1-Artigo5.pdf

Mercuri, E. (1994). Condições para o estudo, segundo depoimentos de alunos e professores de cursos de graduação. Pro-Posições, 5(1), 61-71. http://periodicos. sbu.unicamp.br/ojs/index.php/proposic/article/ view/8644332/11753

Muhlbeier, A. R. K., \& Mozzaquatro, P. M. (2011). Estilos e estratégias de aprendizagem personalizadas a alunos das modalidades presenciais e a distância. Novas Tecnologias na Educação, 9(1), 1-11. Recuperado de http://www.seer. ufrgs.br/index.php/renote/article/view/21906/12708

Niquini, R. P., Teixeira, L. R., Sousa, C. A., Manelli, R. N., Luz, A. A., Turte-Cavadinha, S. L., \& Fischer, F. M. (2015). Características do trabalho de estudantes universitários associadas ao seu desempenho acadêmico. Educação em Revista, 31(1), 359-381. Recuperado de http://submission.scielo.br/index.php/edur/article/ view/122477
Oliveira, D. E. (2012). Impacto dos estilos de aprendizagem no desempenho acadêmico do ensino de Contabilidade: uma análise dos estudantes da Universidade Federal do Rio Grande do Norte. (Dissertação de Mestrado). Universidade Federal do Rio Grande do Norte, Natal, Brasil.

Oliveira, K. L., \& Oliveira, R. A. M. (2007). Propriedades psicométricas de uma escala de condições de estudo para universitários. Avaliação Psicológica, 6(2), 181-188. http://pepsic.bvsalud.org/pdf/avp/v6n2/v6n2a08.pdf Oliveira, K. L., Boruchovitch, E., \& Santos, A. A. A. (2009). Estratégias de aprendizagem e desempenho acadêmico: evidências de validade. Psicologia: Teoria e Pesquisa (UnB. Impresso), 25, 651-656.

Oliveira, K. L., Santos, A. A. A., \& Scacchetti, F. A. P. (2016). Medidas de estilos de aprendizagem para o ensino fundamental. Psicologia Escolar e Educacional, 20(1), 127136. doi: 10.1590/2175-3539/2015/0201943

Oliveira, R. A. M., \& Oliveira, K. L. (2007). Leitura e condições de estudo em universitários ingressantes. Psic: Revista da Vetor Editora, 8(1), 51-59. Recuperado de http://pepsic.bvsalud.org/pdf/psic/v8n1/v8n1a07.pdf

Santos, C. A., Moraes, C. C., Rodrigues, C. B., \& Evangelista, L. A. (2013). Estilos de Aprendizagem: um estudo empírico com alunos do curso de ciências contábeis da universidade federal de Mato Grosso do Sul. RRCF, 4(2), 156-178. Recuperado de http://institutoateneu.com.br/ojs/index. $\mathrm{php} / \mathrm{RRCF} /$ article/view/90/78

Santos, E., \& Wechsler, S. (2008). Compreensão e consideração dos professores sobre estilos de aprender. Boletim- Academia Paulista de Psicologia, 28, 72-78.

Santos, A. A. A., \& Mognon, J. F. (2010). Estilos de aprendizagem em estudantes universitários. Boletim de Psicologia, 60(133), 229-241. Recuperado de http:// pepsic.bvsalud.org/pdf/bolpsi/v60n133/v60n133a09. pdf

Santos, A. A. A., Amadi, R. G., \& Oliveira, K. L. (2005). Estilos de Aprendizagem e solução de problemas: um estudo com pré-escolares. Interação em Psicologia, 9(1), 1-9. doi: 10.5380/psi.v9i1.3281

Schunk, D. H., \& Zimmerman, B. J. Self - regulation and learning. (2003). Em I.B. Weiner (Ed.), Handbook of psychology. New Jersey: John e Sons, Inc.

Souza, M. R. B., \& Moura, M. G. C. (2016). As teorias da aprendizagem: contextualização e desdobramentos com foco na relação professor e aluno em curso profissional. Revista EJA em Debate, (7), 1-16. http://periodicos.ifsc. edu.br/index.php/EJA/article/view/2087/

Souza, A. L., Murta, C. A. R., \& Leite, L. G. S. (2016). Tecnologia ou metodologia; aplicativos móveis na sala de aula. Anais do XIII Encontro Virtual de Documentação em Software Livre e X Congresso Internacional de Linguagem e Tecnologia. Belo Horizonte, Universidade Federal de Minas Gerais.

Sternberg, R. J. (1987). The psychology of verbal comprehension. Em R. GLASER (Ed.), Advances in instructional psychology (pp. 97-151). Hillsdale, NJ: Eribaum. 
Sternberg, R. J. (2000). Psicologia cognitiva. Tradução Maria Regina Borges Osório. Porto Alegre: Artes Médicas.

Thompson, C., \& Crutchlow, E. (1993). Learning style research: A Critical Review of the literature and implications of nursing education. Journal of Professional Nursing, 9(1), 34-50. doi: 10.1016/8755-7223(93)90084$\mathrm{P}$

Uhrig, K. (2015). Learning styles and strategies for language use in the context of academic reading tasks. System, 50, 21-31. doi: 10.1016/j.system.2015.02.002

Verri, F. R., Garcia, A. R., Zuim, P. R. J., Almeida, E. O., Falcón-Antenucci, R. M., \& Shibayama, R. (2008).
Avaliação da qualidade do sono em grupos com diferentes níveis de desordem temporomandibular. Pesquisa Brasileira em Odontopediatria e Clinica Integrada, 8(8), 165169. doi: 10.4034/1519.0501.2008.0082.0006

Watanabe, O. M., Cassetari, L., Santos, M. L. M., Lombard-Platet, V. L. V., \& Domenico, V. G. C. (2001). Um levantamento dos hábitos dos alunos do curso de psicologia do Centro Universitário FMU. Psikhê: Revista do Curso de Psicologia do Centro Universitário FMU, 6, 60-71.

Zhang, L., \& Sternberg, R. J. (2005). A threefold model of intellectual styles. Educational Psychology Review, 17(1), 1-53. doi: 10.1007/s10648-005-1635-4 